\title{
Anscombe and the Unity of Intention
}

\author{
Noam Melamed \\ Tel Aviv University \\ noammela@tauex.tau.ac.il
}

Reception date: 1-11-2019

Acceptance date: 30-12-2019

\begin{abstract}
The conviction that 'intention' is not semantically ambiguous but has a single and distinctive meaning frames the argument of Anscombe's masterwork Intention. What this meaning is, however, is barely recognizable in her book. One reason for this difficulty is that Intention starts from a threefold division of the appearance of the concept in our natural language and proceeds to develop its various accounts piecemeal. Another is the obscurity of the notion of 'practical knowledge' it introduces, precisely for shedding the light that would make its topic perspicuous as a whole. The present article aims to amend this obscurity by providing both a schema of unity for the various parts of the division and an account of the fixed character of the concept. For the former task, the article recaptures Anscombe's technical use of the term 'a kind of statement', uses it to clarify the nature of the division's parts, and argues that they are co-constituted in a larger context of rational proceedings. Having done this, the article shows that the point of such proceedings is to display the validity of practical reasoning in a given case. It analyses Anscombe's account of this kind of validity, providing thereby the representation of the fixed character of 'intention' as a distinct form of thinking.

Keywords: action; rationality; assertion and expression of intention; practical reasoning; practical self-consciousness
\end{abstract}

\section{Resum. Anscombe i la unitat d'Intention}

La convicció que la «intenció» no canvia de significat en diversos contextos, sinó que ha de representar un concepte únic i distintiu, emmarca l'argument de G.E.M. Anscombe a Intention; tanmateix, l'explicació d'aquest concepte i l'esquema de la seva unitat general gairebé no es reconeixen en el seu llibre. Una de les raons és que Intention parteix d'una triple presentació del concepte en el nostre llenguatge natural i desenvolupa aquests aspectes de forma fragmentària. Una altra és l'obscuritat de la noció de coneixement pràctic que introdueix, precisament per aclarir allò que faria que el tema fos perspicu en conjunt. Aquest article repara l'obscuritat tornant a capturar primer els trets de la lògica filosòfica d'Anscombe i utilitzant-los per explicar la triple divisió i la seva coconstitució en un context més ampli de conducta racional. Un cop fet això, la recerca de l'epistemologia de l'acció deriva cap a l'enfocament de la lògica d'Anscombe, on es fa més clar que aquest context més ampli mostra una forma diferent de pensar.

Paraules clau: acció; racionalitat; afirmació i expressió de la intenció; raonament pràctic; autoconsciència pràctica 


\title{
Summary
}
Introduction
4. The single account
1. Anscombe's conviction
5. Conclusion
2. Kinds of statement
Bibliographical references

3. Co-constitution

\begin{abstract}
One would like to say that these two kinds of use do not yield a single meaning; the union under one head, effected by the same word, is an inessential coincidence.
\end{abstract}

Ludwig Wittgenstein, Philosophical Investigations $\$ 561$

\section{Introduction}

This article unfolds what I will call Anscombe's 'conviction' that the different kinds of use associated with the word 'intention' do yield a single meaning, and that their union under one head is not accidental, but rather, that it is essential. This conviction appears at the outset of Anscombe's illustrious book Intention ([1957] 1963; henceforth I) by way of a puzzle about the nature of unity and division of the 'language of intention'. The book pursues an account that would remove the puzzle, yet its piecemeal approach of conceptual analysis seems to hinder the attempt, as it obscures precisely the structural characterization of the concept as a whole. The task of the present article is to work through the puzzle with a clearer notion of the pieces' nature, to show how they are connected and to make the character of the concept perspicuous.

\section{Anscombe's conviction}

According to Anscombe, any elucidation of the concept of 'intention' must explain the following division:

[1] Very often, when a man says, 'I am going to do such-and-such', we should say that this was an expression of intention. [2] We also sometimes speak of an action as intentional, and [3] we may also ask with what intention the thing was done. In each case we employ a concept of 'intention'; now if we set out to describe this concept, and took only one of these three kinds of statement as containing our whole topic, we might very likely say things about what 'intention' means which it would be false to say in one of the other cases... But in fact it is implausible to say that the word is equivocal as it occurs in these different cases. $(I, \$ 1)$

Evidently, the threefold division Anscombe describes here - under the headings [1] 'expression of intention', [2] 'intentional action', and [3] 'intention with which' - is characterized by her as both a division into cases of 
employing a concept of 'intention' and into three kinds of statement. The former characterization is ambiguous, since the phrase 'In each case we employ a concept of "intention" may either mean that in each case we employ a different concept of 'intention', or, with Anscombe's conviction held fast (here stated as a rejection of the word's equivocality), it may mean that in employing a concept of 'intention' in each case, we employ one and the same concept - the concept of 'intention'. The latter interpretation would not be ungrammatical, for in saying, for instance, that in each style of drawing we use a pencil, we allow the possibility of meaning the single pencil that we have. Still this interpretation raises the question about the nature of the division, for if we have just one concept, what sense can we make of the difference in its so-called "employments"?

This question leads back to the notion of 'kinds of statement', and to the question of how the two characterizations of the division relate to each other. There are two ways in which to construe their relation that accord with the aforementioned ambiguity. Assuming three different senses of 'intention', each can be said to correspond to a different kind of statement, so that to make a statement of one of these kinds just is to employ one of these different concepts. Here the word is equivocal and its senses homonymous (Homonymy Thesis). The alternative accords with excluding the possibility that there is more than one concept of 'intention'. In this construal 'to employ $a$ concept of "intention" means to make a kind of statement in which a single meaning or semantic character is recognizable (Single Account Thesis).

The thesis of homonymy is not innocuous. Its conflict with Anscombe's conviction creates the philosophical anxiety that our understanding of the concept is incoherent, as Anscombe says, "where we are tempted to speak of 'different senses' of a word which is clearly not equivocal, we may infer that we are in fact pretty much in the dark about the character of the concept which it represents" $(I, \$ 1)$. Indeed, the thesis of a single account, which Anscombe's conviction postulates, is abstruse precisely because we lack an understanding of the division in which the concept appears and its schema of unity. Consequentially, the 'temptation' to diversity raises Anscombe's puzzle about the unity of intention, i.e., about there being one concept at all, its schema of unity and its single meaning; whereas the 'conviction' of unity creates the task of elucidating the role of 'kinds of statement' in such an account, and of further describing the three kinds of statement of the concept.

In what follows, the single account is approached by establishing the three kinds of statement of the one concept of 'intention' and dissolving the impression of homonymy. The schema of unity is then elucidated in two complementing parts. It is first shown how the three kinds of statement build and operate a linguistic practice embedded prominently in our practical lives. Here unity is presented through the primacy of the whole over its constituent parts. It is then argued that this practice is meant to display a form of reasoning and sets forth its characteristic features. Here the sort of unity implied is that of a distinctive form our thinking takes when it turns to actions. 


\section{Kinds of statement}

On the present view, Anscombe proposes that to employ a concept of 'intention' is to make one of three kinds of statement of the concept of 'intention'. Her use of this technical term is obscure but it can be illuminated by means of Peter Geach's "Kinds of Statement" (henceforth KS) and Anscombe's posthumous "Belief and Thought" (henceforth BT). ${ }^{1}$ In KS, Geach treats 'statement' as a grammatical instrument that applies to sentences, akin to 'question', 'command', or 'request'. Eschewing a unifying formal definition of 'statement', he draws distinctions between statement kinds according to their logical roles, which can be conceived of as the teleology of the instrument at hand (as what a bit of language is meant to $d o) .{ }^{2}$ Let us glean his examples to see how logical roles define statement kinds.

Though not announced as such, Geach's first example of a logical role is the 'proposition'. What a proposition does is show how things stand, which may be either true or false, without it being said which - i.e., without its being asserted. Geach argues that, as opposed to propositions, there is no such thing as the logical role that all statements play. There is however a "typical" one "played by very many", which he labels "normal": that of an asserted proposition, i.e., an assertion. Thus, according to Geach, what a normal statement does is say how things stand. For example, insofar as the fiction 'The pale-blue donkey made peace in the land' is asserted, it does not merely convey a thought but reports something as a truth which is meant to be believed. Such is the role of the normal statement. ${ }^{3}$

Non-normal statements, on the other hand, do other things than assert. 'I promise so-and-so' is an example. An 'I promise' statement, Geach says, "is not an asserted proposition about the speaker, that he does promise so-and-so, but enacts the speaker's promise of so-and-so" (KS: 223). Here the performance of the sentence is the creation of a promise, which marks out a standard logical role that such sentences can play. ${ }^{4}$ Another, at present pertinent, exam-

1. KS does not offer a systematic treatment of the notion in its title, but a defense of the claim that the concept of 'truth' is unique by criticizing the proliferation of statement-kind-specific notions of truth. The locus classicus of the statement-kind notion in Frege is Frege (1917-1918: 329). In Wittgenstein it is relevantly invoked in Wittgenstein (1937-1938); and, significantly, in Philosophical Investigations, first, upon introducing 'language type'/language game' (Wittgenstein, 2009, \$23), and a second time in an instruction on method (ibid.: $\$ 90$ ).

2. Anscombe offers a blanket, disjunctive definition: "Let us adopt the term 'statement' to cover both assertions and utterances in propositional form which do not express thought that ..." (BT: 180).

3. The presentation here is sufficiently narrow to find agreement between Geach and Anscombe. However, it ought to be recognized how Anscombe had broken with Geach's conception of 'the Frege Point' (promulgated in Geach 1960, 1961, 1963, 1991: 14, 16 and KS), reverting her early verdict that "Assertion has only a psychological sense" (Anscombe, [1959] 1971: 116). Her context-sensitive account of the logical character of assertion, which extends one by Julie M. Jack (née Rountree), takes shape in BT.

4. Both Geach and Anscombe accept J. L. Austin's original account of performatives but criticize its subsequent attempted extensions (see KS: 226-228 and BT: 170-174). 
ple of a non-normal statement Geach provides is 'I intend so-and-so'. The logical role of an 'I intend' statement, he says, is not a performance that brings an intention into existence, for "to say 'I intend' never constitutes an intention" (KS: 227). ${ }^{5}$ Nor is it an assertion that merely imparts something future concerning the speaker, for that conflates it with what a prediction does (cp. I, $\$ \$$ 2-3). Rather, following Anscombe, Geach calls the logical role of an 'I intend' statement an expressed intention. He is thus implicitly identifying what Anscombe calls 'expression of intention (for the future)' ( $I$, iii; $\$ 1$ ) as an independent, non-assertive and non-performative kind of statement on the basis of a difference in logical role.

Geach thus opens a way to proceed with the clarification of Anscombe's three kinds of statement. Significantly, his account marks the distinction between expressing something and asserting something, a distinction which Anscombe also clearly draws in BT. I argue that the same distinction applies to the difference between an expression of intention (the first kind of statement, enumerated in [1] above) and our speaking of something as intentional (the second kind of statement, [2] above).

To see this, let us start from Anscombe's fundamental doctrine of acting 'under a description'. ${ }^{6}$ With regard to the knowledge of the one who is acting, she writes, "to say that a man knows he is doing $\mathrm{X}$ is to give a description of what he is doing under which he knows it" $(I, \$ 6: 12)$. With regard to logical roles, one sees that such an action description $\mathrm{X}$ has the role of a proposition that can occur asserted or unasserted (it is a presentation of a happening) and to give it is to make an assertion. But here the description applies to something done knowingly without specifying what kind of knowledge is at stake. Anscombe qualifies this when she discusses our speaking of an action as intentional, "the intentional character of the action cannot be asserted without giving the description under which it is intentional, since the same action can be intentional under one description and unintentional under another" ( $I, \$ 19: 28$; emphasis added). Here the intentional character of the action is a specific kind of knowledge ascribed to the agent under the given description. To assert it is to speak of what happens as intentional: it is to say what someone is doing, to give a proposition which is meant to be believed. Hence, the logical role of Anscombe's second kind of statement is assertion.

The standard way in which a statement of the second kind is made assumes a describer that can tell the intentional character of what happens straight off the conduct, that is, by observation. It may be called 'knowledge from obser-

5. Geach and Anscombe share this dictum. Anscombe views "anything which was deliberately performed as an 'act of intending"' $(I, \$ 27: 47)$, if not "obvious bosh" $(I, \$ 25: 42)$, then as at least inconclusive for ascertaining the intention with which an action is done. Further yet, in a brief diagnosis of a modern cause for the corrupt use of the principle of double effect, she criticizes the theory by which one can "direct" one's intention at will by a deliberate mental act as "a marvellous way... of making any action lawful" (Anscombe, 1961: 59).

6. Anscombe introduces the notion in Intention's $\$ 6$ and stands by it as late as Anscombe (1979). 
vation' in order to align it with a fact Anscombe points to at the beginning of her discussion of intentional action: "We can simply say 'Look at a man and say what he is doing' - i.e. say what would immediately come to your mind as a report to give someone who could not see him and who wanted to know what was to be seen in that place" $(I, \S 4: 8)$. Here the instruction seeks, and the report provides what Anscombe calls "a straight-off description", under which what is happening is called (un)intentional. "I am sitting in a chair writing, and anyone grown to the age of reason in the same world would know this as soon as he saw me, and in general it would be his first account of what I was doing" (ibid.). Thus, mediated or not, the second kind of statement is construed as the proper answer to a question whose general form is "What is X doing?" (the action-variant of the canonical question for assertion "What is the case?"). For example: "What is she doing?" - "[straight-off:] She's sitting in a chair writing"; "What is that cat up to?" - "[evaluates evidence:] It's lying in wait for that pigeon". The point of these answers is not to put forward for consideration the way things are as in an unasserted proposition, but to assert/say/report that something is so. Moreover, to speak of the intentional character of what is happening by reference to such a description - to say, for example, ' $\mathrm{NN}$ is $A$-ing intentionally' - is to use the second kind of statement diagnostically, usually because it has consequences that matter to us. This diagnostical form extends the standard statement of the second kind.

Consider now how the contrast between assertion and expression constitutes the division between Anscombe's first and second kinds of statement. To do so it is helpful to recall how the first kind of statement governs a sentence's sense, as when, in Anscombe's demonstration, "I am going to fail in this exam" $(I, \S 2: 2)$ is not an estimation of one's chances nor a prediction but an expressed intention. What this draws attention to is the fact that an expressed intention voices how things stand with oneself, in particular, one's own idea of one's own action (whether present or proposed), whereas, by contrast, an assertion about an action reports it as another's action. As said, such a report implicitly ascribes a certain intention to the one acting, and though the description seems to apply, the very claim that it is done intentionally or even knowingly might not. This implies that the ultimate test for whether the report is true cannot be another diagnosis but only one's profession, i.e., an expression of intention. Moreover, one's own diagnosis of what one oneself is doing would also be unhelpful, for such a report about oneself entails ascribing an intention to oneself and once again requires inquiring whether it holds (conversely, neither can another express one's own intention, even if they share it, but only reproduce, quote, surmise or presume it). ${ }^{7}$ Most radically, a phrase

7. In BT, Anscombe gives two marks that distinguish the grammar of an expression of belief from that of assertion (BT: 174-181). They can be transferred to the present discussion as follows: (1.) 'I intend', 'I'll $A$ ', 'I'm $A$-ing', etc. cannot go into an if-clause as expressions of intention; (2.) the expressed intention 'I'm $A$-ing, but (perhaps) I'm not $A$-ing' is unobjectionable only when the first occurrence is an expressed intention and the second a report from observation (e.g., the case of writing without looking, as in $I, \$ 29$ : 53; $\$ \$ 45-46$ ). 
of the form 'I'm $A$-ing' can either express an intention or, in an assertive use, report what is up with oneself self-alienatedly. Thus, into a report there is built in alienation from the logos of the acting cause, and, strictly speaking, when that cause is oneself, a self-diagnosis is a form of self-alienated knowledge. ${ }^{8}$ This marks the difference separating the first and second kinds of statement. It points to the insight that an assertion is meant to provide theoretical knowledge derived from the action as it is known as another's action (from observation broadly conceived), whereas an expressed intention is meant to voice one's self-understanding as the acting cause - a practical bit of knowledge (invoking $I, \S 48: 87)$.

Anscombe had introduced the third kind of statement as follows, "We may ask with what intention an action was done" $(I, \$ 1)$. We may, that is, put forward the question 'Why?' in her special sense: 'Why are you $A$-ing?'. What might mislead at first is to view the logical role of the third kind of statement as this question taken in isolation. However, embedded in that very question is the assertion 'You are $A$-ing', a statement of the second kind, which creates room for rejecting the description or providing another. Now, although absolutely anything could be said or done in response to the question, an answer is adequate only if it is an expression of intention, a statement of the first kind. But again, this requirement might mislead one into viewing the answer in isolation as the locus of the third kind of statement and would effectively collapse the third kind of statement into the first kind and miss Anscombe's distinction. What should be done to avoid this is to take the pair of statements - the assertion embedded in the question and the expressed intention in the reply - as co-constitutive of one and the same context of a petition: a question and answer exchange which is an appeal for a reason for acting, or a further description of the action. It is in this context that the question asks for and the answer provides the intention with which an action is done. ${ }^{9}$

This dyadic context of petition is essential for making explicit a proper statement of the third kind. It emerges most naturally when we compose a statement from the description in the 'Why?' question and the expressed intention given as its answer. For example, the sentence 'I must inform NN about X' in the context of being the answer to the question 'Why are you writing?', forms the basis for composing the statement 'I am writing to inform NN about X'; likewise, the noun phrase 'The Piero della Francesca frescoes' given in answer

8. Self-alienated knowledge of one's own action includes what one may observe oneself doing without intending or wanting to, like unintentionally "sliding on ice" ( $I, \$ 47: 85)$, or like segments of the infinitely scrutinizable manifold of gestures that make up any intentional action. It may also be a report from observation of what one is doing when the acting is not spontaneous but follows another 'voice', e.g., in drawing a shape in the mirror relying only on the visual image (Wittgenstein, 1961: 87). Consider in this connection, too, that the action descriptions populating Wittgenstein's imagined book The World as I Found It $(1963, \$ 5.631)$ can be of either sort.

9. I've picked up and modified this elegant turn of phrase from Moran and Stone (2011: 34). 
to 'Why are you travelling to Arezzo?' is an ellipsis which assumes the role of an expressed intention, and forms the basis for composing the statement 'I'm travelling to Arezzo for [to marvel at] the Piero della Francesca's frescoes'. We thus have the schema ' $<$ the intention expressed in the answer $>$ is the intention with which $<$ the action asserted in the question $>$ is done.'

What is distinctive about the third kind of statement, and therefore sidesteps collapse into the first kind, is evident from the linguistic means used for composing a complete statement of this kind from the two descriptions: the 'fixed' one and the one 'further' in relation to it. These 'means' include prepositions as applied in ' $A$ for $B$ ', ' $A$ to $B$ ', or the conjunction ' $A$ because $B$ '. They connect up a teleological structure of explanation or justification, akin to what Anselm Müller lays down as the canonical form of practical reasoning (Müller, 1979: 92). Such 'teleological connectors' are indispensable for forming a proper statement of the third kind. For one may remove the action description in the question and make a truncated statement of this kind: e.g., 'To inform NN' or 'For the frescoes'; but were one to reject their use (and in that deny a reason), the answers would disrupt the context of petition turning statements of the third kind into those of the first: e.g., 'Why are you writing?' - 'I will inform NN; (but) I'm not writing for that', 'Why are you travelling to Arezzo?' - 'I intend to see the frescoes; (but) I'm not going because of that.'

This then can be called a genuine statement of the third kind, complete or truncated, and fruitfully contrasted with a quasi-statement of this kind. 'Quasi' indicates statements of the third-kind structure whose second element is not an expressed intention but an assertion. These have the form ' $S$ is $A$-ing to $B$ ', e.g., "She is writing to inform NN"; "He is travelling to see the frescoes". In these cases, the speaker's statement does not express the intention of another but is an assertion about it (made from observation or testimony, inference, guesswork, shared action, etc.). Now it is not this variety that Anscombe holds primarily in mind in addressing the third kind. Indeed, unlike these quasithird-kind statements, the genuine ones are not what Geach calls normal. In an expression of the intention with which an action is done one gives the point, the use, the good of doing something, or - what is a major theme of Anscombe's Intention - one's reason for acting. Such statements explain, justify, interpret, or, broadly speaking rationalize an action - typically in one teleological mode or other. In sum, the logical role of the third kind of statement is that of rationalization.

Does each kind of statement convey a separate content of its own that is not necessarily shared in a given case with the other two? Showing that they do would confirm the Homonymy Thesis and reject Anscombe's conviction. In $I \$ 1$, Anscombe elicits these so-called senses of 'intention', only to refute their independent standing in the transitional $\$ \$ 19-20$ (discussed in the next section). The alleged differentiating sense of 'intention' in expressions of intention is identified as concern with the future; in speaking of something as intention- 
al it is a feature that pertains to what is going on here and now, i.e., to the intention to do, or of doing, what one is ostensibly doing; and in speaking of the intention with which an action is done, it is a further something that someone aims at in his actions.

Before sharpening the contrast, it can already be ascertained that the so-called senses of 'intention' in 'an expressed intention' and in 'intention with which' are co-extensive: (i.) Expressing intention for the future without having that intention would ipso facto make it a statement of a different kind, i.e., a lie (cp. $I, \$ 2: 4-5$ ); conversely, although one's intention needn't be expressed to exist, it cannot altogether escape the capacity to so be (say, upon being petitioned); (ii.) Although Anscombe begins with the constraint that "the further intention with which a man does what he does" is an "intention for the future" $(I, \$ 20: 31)$, and the parallel one that an expression of intention is always prospective, she breaks this mold to allow further intention in the present: "we must presumably allow the further intention with which he is doing $\mathrm{X}$, say $\mathrm{Y}$, so long as it is reasonable to say that he is doing $\mathrm{Y}$ in, and at the same time as, doing X" (ibid.). With this Anscombe captures how we advert to the wider context of one and the same present activity $(I, \$ 22$ : 34-35). She generalizes the point later on, writing:

The mark [of further intention] is [that it is] at a distance from the immediate action... it may be at a distance in various ways... 'resting' is merely a wider description of what I am perhaps doing in lying on my bed... whereas getting in the good government is remote in time from the act of pumping, and the replenishment of the house water supply... is at some spatial distance from the act of pumping. (I, $\$ 41: 79)$.

From this we can conclude that the expression of the intention with which someone is doing something is not restricted to being future, because 'being future' is among the modes of that intention's 'being further', and further intentions in the present get expressed just as well (e.g., 'I'm resting').

Ultimately, then, the contrast between the so-called senses rests on the idea that it is possible to conceive of an action $A$ either as done in view of an aim or as one for which such a thing is not forthcoming. Put differently, a question as to $A$ 's purpose ('Why are you $A$-ing?') might provide that purpose or turn out empty ('For no reason at all'; 'I don't know why, I just am'); but either way what is common is quite simply $A$; and so it seems that $A$ has the character of being intentional whether or not a reason for it is provided. ${ }^{10}$ Can this mark out an independent concept of 'intention', one conveyed in speaking of something as 'intentional' apart from what 'intention' conveys in the other two cases?

10. This is what the expression 'a man's intention simpliciter' $(I, \$ 1)$ signifies. Anscombe had probably adopted 'simpliciter' from Geach (1956: 34, 40). 


\section{Co-constitution}

How can it be shown that the intentional character of an action (its "intentionalness" [Anscombe, 1982: 216-218, 223]) cannot exist apart from what 'intention' conveys in the two other cases? $I \$ \$ 19-20$ take up this task by arguing for two theses:

(1) No Material Independence: its existence does not depend on any actuality other than that of the action itself - i.e., on anything that coincides with an action $(I, \S 19)$.

(2) No Formal Independence: its existence cannot be conceived without what 'intention' conveys in expressions of intention and the further intention in acting $(I, \S 20)$.

These amount to the negative claim that intentionalness is not independently constituted, and lead to a positive claim:

(3) Co-Constitution: the three kinds of statement of 'intention' are co-constituted.

What follows is a brief presentation of these theses, the last of which leads to the single account of 'intention'.

Is the so-called sense of 'intention' in speaking of an action as intentional materially independent of its sense in the two other cases? It is the task of $I$ $\$ 19$ to disable an empiricistic picture of the mind that might grant as much. According to that picture what we do by describing an action as intentional is assume an additional mark of intention 'Int "which exists when [the action] is performed" ( $\$ 19: 28)$. Int is an experienceable mental episode: either something perceived (a mental event, $\$ 11: 17)$, or an "interior performance" ( $\$ 27$ : 47) like making "a little speech to oneself" to 'constitute' an intention $(\$ 25: 42)$, or perhaps an underlying Hobbesian 'endeavour' (Hobbes, 1651: 34). It is plain that Int and the action itself differ in kind, and so in kind of description. Yet, in thus viewing Int one also views that which it allegedly makes intentional as intentionless. This "preintentional" ( $\$ 19: 28)$ aspect of the action conveys "bodily movements in a purely physical description" ( $\$ 7$ : 13). So, the empiricistic picture of $\$ 19$ suggests that a movement represented preintentionally may also be called an intentional action only if it is accompanied by an experienceable mark of intention. Designating the former 'Pre' produces the arithmetic: Pre $+\operatorname{Int}=A$.

Now in this dualistic constitution of action, the description under which we call an action 'intentional' $(A)$ turns into a mere label for the co-incidence $(+)$ of two other descriptions (Pre, Int). Anscombe argues that on this summation of mental and physical incidents, as it were, the picture falls. ${ }^{11}$ The error,

11. For further discussion of this arithmetic see Ford (2011). 
she claims, lies not so much in the reification of intentions into experienceable episodes, as in granting them constitutive power. The power is granted by taking the phenomenal mark-of-intending as somehow bearing the right sense on its face. Yet as soon as Int is provided, the question of whether it is meant and how, viciously returns. In light of this, "it is a mere happy accident that an $[$ Int $]$ relevant to the wider context and further consequences ever accompanies the preintentional movements in which a man performs a given intentional action" ( $\$ 19: 29)$. Moreover, to reject the coincidental constitution of intentional actions, is also to reject the claim that the preintentinal describes their truly fundamental reality. This is so because, divorced of such reified Ints, the accompanied preintentional movements can no longer be intelligible as actions at all. As Anscombe concludes, "the only events to consider are intentional actions themselves, and to call an action intentional is to say it is intentional under some description that we give (or could give) of it" ( $\$ 19$ : 29). This corollary and No Material Independence are two sides of the same coin, which in fact reinforces the Single Account Thesis. For if the intentional character of an action (e.g., lifting) does not depend on any observable description (a purely physical 'muscles contracting' or a mental "lift!" or <grunt $>$ ), then there must be something about the description itself that conveys it: the intentional character does not depend on a differently described content but on a difference in the form of description.

Is the so-called sense of 'intention' in speaking of something as intentional formally independent of its sense in the other two cases (Formal Independence)? In $\$ 20$, Anscombe shows how thinking so would implicate us in one of several false pictures of the 'intentionalness' of intentional actions. As she has it, an action's intentional character is distinguishable by the applicability of the question 'Why?' with answers that give reasons for acting. $I \$ 20$ demonstrates the incongruities that arise between her account of this applicability and various other senses that the question has by how it applies to makeshift ranges that the supposition of independence engenders. The arguments in $\$ 20$ rely on Anscombe's account in all its subtlety, and mostly lay outside the present focus. It should be sufficient here to present their general scheme and a way in which the crucial distinction between value and calculation emerges in it.

The general scheme is as follows. To test Formal Independence, Anscombe makes two suppositions, the absolute one: "(a) Suppose that 'intention' only occurred as it occurs in "intentional action", and the reasons-excluding one "(b) suppose that the only answer to the question 'Why are you X-ing?', granted that the question is not refused application, were 'I just am, that's all'" $(\$ 20$ : 30). Supposition $(a)$ is then given two major interpretations: one construes intentionalness as a style-characteristic or 'look' of an action (a.1.), which can be further interpreted in a naïve (a.1.1.) or a sophisticated manner (a.1.2.); the other construes it as a characteristic of the action's motive (a.2.), which can be further interpreted as either sentimental (a.2.1.) or as desidera- 
tive (a.2.2.). Supposition (b) presents a rather stunted version of 'intentionalness' and is assessed vis-à-vis the detailed scale of kinds of description in Anscombe's account - from involuntary movements to a variety of voluntary action kinds and on to the intentional ones. One by one these supposed conceptions of 'intentionalness' are shown to be false, and the two suppositions are rejected.

Let us now briefly expand on just (a.2.2.). This version concedes the necessity of 'agential knowledge' as a mark of intentionalness - i.e., the necessity that the agent herself can say without observation what she is doing - but excludes the intentional action's concern with the future. In this Future-Free picture, the question 'Why?' applies to positive answers only if they give a backward-looking motive or a sentimental one. Anscombe now emphatically asks, "Is motive enough to constitute intentional actions as a special kind?" (\$20:31). Her 'No' invokes a tacit fact about our concept of 'motives', namely the rational practice of questioning them, and adds quite obscurely that this practice would lose its point if intentions for the future were out of the picture $(\$ 20: 31-32)$.

To clarify Anscombe's remark, recall a general point she makes about questioning a proposed action that has a backward-looking motive. She writes, "it is a mistake to think one cannot choose whether to act from a motive. Plato saying to a slave 'I should beat you if I were not angry' would be a case" ( $\$ 14: 22)$. According to the anecdote, as recounted by Seneca, Plato takes himself not to be at fault for deciding to beat his slave; on the contrary, he has a right to do so as an act of administering law. The wrong in his eye is his motive, motive qua-sentiment and qua-desire, his beating in angry revenge (contrast with a cold bureaucratic desire for revenge). Perceiving this, Seneca's Plato gives up his right and instead resolves to inflict punishment upon himself for it, explaining, in Seneca's words: "I'm punishing an angry man" (Seneca, 2010: 73). This figure concerns the future in two ways. First, as a measure of action, it is made sense of by a duty to avoid a predicted wrong: "I'm angry,' he said, 'and I'll do more than I should, and more gladly; that slave shouldn't be in the control of one who can't control himself'" (ibid.). Second, as a measure of character, it is quite explicitly forward-looking: "[the judge who is free of anger] will always, whenever he imposes punishment, keep this principle in mind: one penalty is inflicted to correct the wicked, another to destroy them. In either case he will keep his eye on the future, not the past (for as Plato [Laws XI 934a6-b2] says a sensible man punishes, not because a wrong has been done, but lest one be done; what's done is beyond recall, what's to come can be prevented)" (Seneca, 2010: 31-32). So, as vengeance only looks back, one could add to the admonition "I'm punishing a vengeful man". This explains how the capacity to attend critically to motives - both sentimental and desiderative - is internal to the cultivation of attunement to ethical failure, and so is governed by an intention for the future. Thus, quite apart from the motive given, the practice of critically assessing it conveys a forward-looking one (=an intention) of a non-sentimental nature and higher architectonic standing. This latter 'archi- 
tectonic end (for Seneca's Plato: justice) governs part of what elsewhere Anscombe, following Aristotle, calls 'acting well'.

The remark in $\$ 20$ thus means that to give a motive that essentially cannot "keep its eye on the future" as answer to the question 'Why?' leaves it unclear why it should, and how it could, be distinguished from an expression of emotion (cp. 'doing out of hatred', $\$ 12: 18-19)$ or an hedonic appetition (cp. 'making a mere return', $\$ 35: 65-66$ ). The gist of it is that this, along with all the other supposed 'conceptions' of intentionalness, though they might clarify an action's worth or meaning, cannot ascribe to it rational calculation, which is the point of asking 'Why?' in the special sense (recall the teleological account of the third kind of statement above). It so transpires that 'intentionalness' does not signify a self-standing concept.

It is now possible to look at the whole account of the question 'Why?' and the answer-types that specify its point as onto a linguistic practice and see that it is a practice for establishing the validity of an action (a kind of rationality). This would give a more determinate sense to the thesis of Co-Constitution, since the three kinds of statement are co-constituted in this linguistic practice. The ability to participate in this practice, to give and ask for its type of answers, is very general and so quite useful for giving a distinct sense in which an action is up to us: a sense in which it is stamped rational, rightly or wrongly.

What grounds the three kinds of statement of intention is a form of thinking in the presentation of which they partake. The three emerge, in other words, as co-constituent parts of a single, logically prior whole: the practice for establishing an action's validity by giving and asking for reasons for acting. Intention’s $\$ 21$ makes explicit this practice’s constitutive role,

we can see why some chain [linking action and end] must at any rate begin. As we have seen, this does not mean that an action cannot be called voluntary or intentional unless the agent has an end in view [e.g., it may have a sentimental motive]; it means that the concept [qua kind of statement] of voluntary or intentional action would not exist, if the question 'Why?' with answers that give reasons for acting, did not. $(I, \$ 21: 34)$

The linguistic practice is presented here as a means for the representation of an action's rational order ('the order of intention'). This order is schematized as a chain (a teleological one) that the practice unfolds. Before clarifying how it does so, consider briefly what it is for a practice to condition the existence of a concept, here a kind of statement; what kind of conditioning is it? The practice in question, as said, is conceived of as a means for representing the order of intention, and 'a means of representation' is the ground of the unity of its constituent parts. The concept of the practice is thus one of internal teleology analogous, for example, to that of a clock. A clock is meant to represent a value by means of, e.g., its hands and their position. The primacy of the whole over the parts means that the point of the whole governs the roles of its parts, and in that constitutes their 'concepts' ('a hand', 'a position'), and their mode of 
joint intelligibility ('the time'). This is the kind of ground that Anscombe's concept of "the question 'Why?" with answers that give reasons for acting" provides. In the same way, I argue, this linguistic practice is the condition of existence of the three kinds of statement of intention.

Granted that some chains must begin, consider how they are made according to Anscombe's account of 'intention with which' in $I, \$ \$ 22,23$ and 26. A further intention in acting may be a thing of the future or a wider description of the action in the present tense. But what is it that makes a description 'a further intention' in each case? For the former case Anscombe gives her "vague and general formula" that the further description $q$ is a later stage of a totality of proceedings in which the description $p$ is an earlier stage $(I, \$ 22: 36)$. The case of wider description, on the other hand, is explained by a recursive procedure. The base of the procedure is an action description, ' $A$-ing', and it proceeds by applying the question 'Why?' to it, 'Why are you $A$-ing?', and getting an answer $\mathrm{X}$ which is required to be a reason for acting. To this answer the following condition is applied: if $\mathrm{X}$ provides an adequate further description of the action, then call this procedure on $i$, otherwise stop and assess the case. The procedure's protocol consists in a chain of descriptions (Anscombe represents it A-B-C-D at $\$ 26: 45$ ), where at any point in the series, the last perhaps tentative description is called the intention with which the action is done (so after one round $B$, after two $C$, and after three $D$ is the intention with which $A$ is done; for illustration see the well-known example of the house-aid pumping water in $I$, $\$ \$ 23-26)$.

This already outlines the required sense of the practice as a ground of unity. For the generated chain is an extended statement of the third kind. Hence, the third kind of statement is embedded in this linguistic practice, just like the first and second kinds of statement are embedded in it. The three act together as constituent parts of that which governs their roles. What this is - the point of the practice - requires clarification.

In the recursion, $A$ can be called intentional only if $\mathrm{X}$ provides an adequate further description of $A$-ing. According to Anscombe, $\mathrm{X}$ is an adequate further description of $A$ only if it satisfies two conditions:

$\mathrm{X}$ is accepted: it is an expression of intention (e.g., 'I'm $A$-ing') whose correlative assertion (e.g., ' $S$ is A-ing') holds;

$\mathrm{X}$ is valid: it is intelligible as a reason for $A$-ing, e.g., it is an Anscombean motive.

These conditions illuminate two aspects in the recognition of action: one concerns the applicability of the description to what is happening, the other reflects the assessment of the underlying reasoning that joins it and its predecessors in a practical nexus. The point of the linguistic practice is therefore to find out how what one is up to stands the test of reason. Its constituent means, as I've argued, are the three kinds of statement of the one concept of 'intention'. 


\section{The single account}

So far 'intention' has emerged as signifying the rational order of a practical proposition or its execution in an action. The practice of revealing intentions assumed the form of an extended rationalization, whose point is to test that proposition's validity, that is: to examine the reasoning's form. What, then, is Anscombe's account of the form of practical reasoning?

The answer requires a small detour. Anscombe's procedural concept of rationalization is not the only way to display the order of intention, the same is achieved by Aristotelian deliberation (bouleusis). Of course, Anscombe is anything but ignorant of this (see $I, \mathbb{4} 22: 80$ ), and, in fact, it can be shown that Aristotelian deliberation and Anscombean rationalization are formally identical. ${ }^{12}$ Furthermore, Anscombe views Aristotelian deliberation as "a particular unit of practical reasoning, to which the expression 'practical syllogism' [a pre-formalized inference] is usually restricted" ( $I, \$ 42: 79)$, and in a later essay adds that "to set out the form of practical reasoning is to set out the form of deliberation" (Anscombe, 1965: 72; cp. Aristotle's NE VI.1, 1139a13-14). But 'to set out the form of practical reasoning' means to provide a formal representation of the reasoning in which the arrangement of the signs alone shows its validity - and this is, strictly speaking, a practical inference. It so follows that the form of Anscombean rationalization (the teleological chain) is set out in a practical inference, and the concept of the 'validity' of an action ('practical validity') is that of the validity of the conclusion of a practical inference.

Anscombe's concept of 'practical validity' can be best explored in her later essay "Practical Inference" (henceforth PI). There, Anscombe develops her logical prototype of practical inference, the 'if-then form', vis-à-vis her reconstruction of the Aristotelian one (consequent on $I, \$ \$ 33-42)$. She produces several examples to demonstrate their affinity (PI: 117-18), from which it suffices to consider just one (taken from Metaphysics Z.7, 1032b7-10):

Objective:

Restore the patient's health

\begin{tabular}{|c|c|c|}
\hline \multirow[t]{5}{*}{ Reasoning: } & Aristotelian Form & If-Then Form \\
\hline & Being healthy is being $X$. & $\begin{array}{l}\text { Only if this patient is } \mathrm{X} \text { will he be } \\
\text { healthy. } \\
t \leftarrow s \text { ( } s \text { is necessary for } t \text { ) }\end{array}$ \\
\hline & Only the homogeneous is $\mathrm{X}$. & $\begin{array}{l}\text { Only if he is homogeneous will he be } \mathrm{X} \text {. } \\
s \leftarrow r(r \text { is necessary for } s)\end{array}$ \\
\hline & $\begin{array}{l}\text { Only by heating does the inhomoge- } \\
\text { neous become homogeneous. }\end{array}$ & $\begin{array}{l}\text { Only if he is heated will he become } \\
\text { homogeneous. } \\
r \leftarrow q \text { ( } q \text { is necessary for } r \text { ) }\end{array}$ \\
\hline & Rubbing is heating. & $\begin{array}{l}\text { If he is rubbed, he will be heated. } \\
p \rightarrow q \text { ( } p \text { is sufficient for } q)\end{array}$ \\
\hline
\end{tabular}

Conclusion:

Rub the patient's body

12. With the minor qualification that their directions are reversed and that they differ in the actualization of the conclusion. 
Anscombe emphasizes that the Aristotelian premises justify her form's hypothetical considerations, making them true ones (PI: 118, 120) - e.g., if his body is rubbed, he'll be heated because rubbing is heating - but in effect claims that the two are interconvertible (see PI: 128). Second, like Aristotle, Anscombe does not restrict the means employed in her syllogism to just the necessary ones. As she writes, "in Aristotle's example, the 'homogeneity' is said to be necessary for restoration of health, and heating for homogeneity. Friction, however, is merely a way of producing heat. What is important is surely that the end will be attained by the means arrived at, not whether it is the only means" (PI: 118). Indeed, both thinkers allow means that are necessary or sufficient for attaining the objective. Anscombe's 'if-then form' is therefore a set of interconnected propositions $q, r, s-$ a "unit of reasoning" $(I, \$ 42: 79)$ - that mediates between an objective to have it that $t$ and a conclusion $p$ which is doable in action and is meant to be done (it is a fiat or "quasi-imperative"; PI: 133).

The 'if-then form' is therefore a proof-pattern, a nexus of propositions in which the conclusion follows merely from the way in which the propositions are arranged. It is such a pattern because for it, as Anscombe says, "the logical facts are merely the same as for theoretical [patterns]: e.g., the truth-connexions of $p$, if $p$ then $q$, and $q$; and of not- $p$, only if $p$ then $q$, and not- $q$ " (PI: 139). From this follow two marks of 'practical validity'. In a theoretical respect 'validity' implies that the conclusion preserves the truth of the premises. Yet, as Anscombe writes, "truth is the object of belief, and truth-preservingness an essential associate of validity in theoretical reasoning. The parallel [goodness of the end] will hold for practical reasoning" (PI: 146). So, in a practical respect, 'validity' also implies that the conclusion preserves the value of the end: i.e., the pattern also assures that what is being done is given the value of what it is being done for.

A further, 'teleological' feature of practical validity can be gathered from Anscombe's proposal of two orthogonal measures of ends: generality and perspicuity (PI: 140-147). The generality of an end pertains to the question of who should attain it, quantificationally speaking, whereas its perspicuity pertains to the quality of the conception of what is to be attained. Assessed with the latter, an end may appear to be diffused or clear-cut depending on the degree of genericity/specifity of the set of propositions given of it. Anscombe speaks of this as a matter of form: "what form of wealth, for example, is a man who wants to be wealthy aiming at in his calculations, when he has worked out something to do in order to be wealthy? The possession of lands, or of a regular income, or of a large sum of money? His heart may just be set on being wealthy, but if he is to achieve this it must take a more specific form, perhaps determined for him by his opportunities" (PI: 141). To look closer at this measure, consider Anscombe's other heating example (taken from von Wright 1963 and 1972): 
Generality

\begin{tabular}{|c|c|c|c|}
\hline & & General & Particular \\
\hline \multirow{5}{*}{ 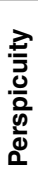 } & Generic & Huts should be inhabitable. & This hut should be inhabitable; \\
\hline & $\hat{i}$ & & ... should be well-heated; \\
\hline & $\dot{v}$ & & ... by a stove; \\
\hline & Specific & & $\ldots$ by a coke stove; \\
\hline & Concrete & & This hut should use this coke stove. \\
\hline
\end{tabular}

Clearly, the descending specification of the end represents a teleological order, wherein the relation between each adjacent pair of propositions is the relation between a measure and a measured: the more generic (e.g., make inhabitable) acting as a standard for the appraisal of the more specific description of the action (e.g., make well-heated), failing which implies the latter's exclusion. But note that each positive appraisal requires justification by another proposition that in itself acts as a constituent part of a correlated Aristotelian/Anscombean inference (e.g., 'This hut should be well-heated' makes more specific 'This should be inhabitable' because 'only well-heated huts are inhabitable'/'Only if it is well-heated will it be inhabitable'). This means that a specification/generization is inferential in nature, and that its concrete imperative is a conclusion whose validity can be assessed in a teleological respect. Thus, 'validity' appears to imply not only proof of truth and value but also correctness of calculation.

These three features characterize Anscombe's concept of 'practical validity'. Practical validity is what a practical inference is meant to display solely in virtue of its structure. And when a round of deliberation/rationalization is played out, that normally is its point. However, it is significant which of the two procedures it is, for in each case what the calculation itself is for differs. First, the reasoning in a deliberation can be a purely theoretical affair, disconnected from willing the objective, when it is propounded as "a classroom example" (I, $\$ 33: 60)$ to show how "we may be able to assert $p$ [the conclusion] and go on to assert $r$ [the objective]" (PI: 128) or vice versa (cp. the exercise in Euclidean geometry at PI: 117). However, the reasoning in a deliberation may also reflect a will for an objective by having its propositions "made the topic of a fiat" (PI: 129), and so show that "we may want to achieve $r$ [the objective] and decide to make $p$ [the conclusion] true" (PI: 128; emphasis added). But, as Anscombe says, only in rationalization is the reasoning properly practical, for only then "the conclusion $[p]$ is an action whose point is shewn by the premises [a mediating $q$ ], which are now, so to speak, on active service" $(I, \S 33: 60)$ - i.e., they serve to rationalize the action (the point is reiterated in PI: 129).

Thus, beyond establishing validity, the question 'Why?' inquires whether and how a bit of reasoning has been put into properly practical use. The ultimate question for formulating the Single Account thus becomes: what is the ground of the possibility of doing so? Anscombe's short answer to this question 
is that the reasoning can assume a practical use only when the considerations in it "concern 'what can be otherwise'... [that] our actions can affect" (PI: 129; cp. $I, \S 22: 35-36) .{ }^{13}$ This dictum encapsulates two aspects of what might be called 'authorship': one's recognition of a reasoning's practical worth, and one's representation of oneself as its acting cause.

For clarifying how a bit of reasoning comes to have practical worth, consider one from Intention: "John will drive from Chartres to Paris at an average of sixty m.p.h., he starts around five, Paris is sixty miles from Chartres, therefore he will arrive at about six" $(I, \$ 33,59-60)$. This is a reasoning for the truth of a proposition, that could take the form of a calculation what to do. It could, for instance, determine what John should do, and so perhaps what John is doing, given that he wants to meet Yoko that evening. The 'demonstration' is not of what will happen but of what should be done, and so of what one should take as instructive, if one so wills. To so embed a segment of reasoning in the context of willing something shifts the mode of its propositions from theoretical to practical (the 'assertibles' are made 'the topic of fiats' doable in action), and also shifts their relation to the topic of the objective from ampliative (adding further theoretical determinations to the object of willing) to explicative (not adding any further objects of willing but only articulating the logical predications of willing the given object). In other words, as practical, the very same theoretically-ampliative propositions are in fact explicative of the larger intention with which the action is to be done, they are so to speak 'practically-explicative' or 'instructive' as we have called it.

But what makes possible the thoroughgoing unity of willing the end and willing the means, i.e., what must be in place for the unity of the context of doing anything? This must be, as said, one's ability to take the description of a way of acting as one's instruction, so that what grounds this possibility is the representation of oneself as an efficient cause acting with a concept as its rule. Ultimately, the first-personal thought of oneself as 'a cause with a rule' - the I think in the practical sense, the I do - is the ground of one's acting intentionally. Thus, within the acting there formally resides the rule (practical reasoning proper), and within the rule there formally resides the $I d o$.

\section{Conclusion}

Let us bring together the elements that make up the single account of 'intention'. The word 'intention' signifies a context of rational authorship of action. 'Rational' signifies practical validity, which implies the preservation of truth, value and correct calculation; 'authorship' signifies practical self-consciousness, which implies recognition of the practical significance of a reasoning and one's self-understanding as one who may or must make it true. The linguistic practice of the question 'Why?' with answers that give reasons for acting assumes

13. Anscombe is invoking Aristotle's distinction between two kinds of rational capacity according to the difference in the form of their objects, see NEVI.1 1139a5-11, 1139b15 ff. 
this concept and constitutes its three kinds of statement. It does not assume any added thing which coincides with the action, but rather, in assuming it, a certain mode of signification through which action can be understood. ${ }^{14}$ Thus, Anscombe's conviction is brought into relief. 'Intention', she teaches, does not signify a proper concept but a formal one.

\section{Bibliographical references}

Anscombe, G. E. M. ([1957] 1963). Intention (2nd ed.). Cambridge, MA; London, England: Harvard University Press, 2000.

- ([1959] 1971). An Introduction to Wittgenstein's Tractatus (4th ed.). South Bend, Indiana: St. Augustine’s Press, 2001.

- (1961). "War and Murder" In: The Collected Philosophical Papers of G. E. M. Anscombe Volume III: Ethics, Religion and Politics. Oxford: Basil Blackwell, 1981, 51-61.

- (1965). "Thought and Action in Aristotle: What is 'Practical Truth?". In: The Collected Philosophical Papers of G. E. M. Anscombe Volume I: From Parmenides to Wittgenstein. Oxford: Basil Blackwell, 1981, 66-77.

- (1970?). "Belief and Thought". In: Geach, Mary and Gormally, Luke (eds.). Logic, Truth and Meaning: Writings by G. E. M. Anscombe. Exeter, UK: Imprint Academic, 2015, 149-181.

- (1974). "Practical Inference". In: Geach, Mary and Gormally, Luke (eds.). Human Life, Action and Ethics: Essays by G. E. M. Anscombe. Exeter: Imprint Academic, 2005, 102-140.

- (1979). "Under a Description". In: The Collected Philosophical Papers of G. E. M. Anscombe Volume II: Metaphysics and the Philosophy of Mind. Oxford: Basil Blackwell, 1981, 208-219.

- (1982). "Action, Intention, and 'Double Effect'". In: Geach, Mary and Gormally, Luke (eds.). Human Life, Action and Ethics: Essays by G. E. M. Anscombe. Exeter, UK: Imprint Academic, 2005, 207-226.

Aristotle (2014). Nicomachean Ethics (C. D. C. Reeve, trans.). Indianapolis, Indiana: Hackett Publishing Company, Inc.

- (2016). Metaphysics (C. D. C. Reeve, trans.). Indianapolis, Indiana: Hackett Publishing Company Inc.

Ford, Anton (2011). "Action and Generality". In: Ford, Anton; Hornsby, Jennifer and Stoutland, Federick (eds.). Essays on Anscombe's Intention. Cambridge, Mass.; London, UK: Harvard University Press, 76-104.

Frege, Gottlob (1917-1918). "Thought". In: Beaney, Michael (ed.). The Frege Reader. Oxford: Blackwell Publishers Ltd., 1997, 325-345.

Geach, Peter T. (1956). "Good and Evil". Analysis, 17 (2), 33-42.

- (1960). "Ascriptivism". In: Logic Matters. Oxford: Basil Blackwell, 1972, 250-254.

14. As per the account of practical knowledge, 'intention' signifies the formal concept through which the object of practical knowledge is represented. 
— (1961). "Frege". In: Three Philosophers. Ithaca, New York: Cornell University Press, 127-162.

- (1963). “Assertion”. In: Logic Matters. Oxford: Basil Blackwell, 1972, 254267.

- (1979). "Kinds of Statement". In: Diamond, Cora and Teichman, Jenny (eds.). Intention and Intentionality: Essays in Honour of G. E. M. Anscombe. Ithaca, NY: Cornell University Press, 221-235.

- (1991). "A Philosophical Autobiography". In: Lewis, Harry (ed.). Peter Geach: Philosophical Encounters. Dordrecht, Netherlands: Kluwer Academic Publishers, 1-25.

Новвеs, Thomas (1651). Leviathan. New York: Oxford University Press, 1998.

Moran, Richard and Stone, Martin J. (2011). "Anscombe on Expression of Intention: An Exegesis". In: Ford, Anton; Hornsby, Jennifer and STOuTLAND, Frederick (eds.). Essays on Anscombe's Intention. Cambridge, MA; London, England: Harvard University Press, 33-75.

Müller, Anselm (1979). "How Theoretical is Practical Reason?”. In: DiaMOND, Cora and Teichman, Jenny (eds.). Intention and Intentionality: Essays in Honour of G. E. M. Anscombe. Ithaca, NY: Cornell University Press, 91-108.

Plato (1997). Laws. In: Cooper, J. M. and Hutchinson, D. S. (eds.). Complete Works. Indianapolis, Indiana: Hackett Publishing Company, 13181616.

Seneca, L. A. (2010). On Anger. In: Anger, Mercy, Revenge (Robert A. Kaster and Martha C. Nussbaum, trans.). Chicago, Illinois: The University of Chicago Press, 3-129.

Von Wright, Georg Henrik (1963). "Practical Inference". In: Practical Reason: Philosophical Papers of Georg Henrik von Wright, Vol. I. Oxford: Basil Blackwell, 1983, 1-17.

- (1972). "On So-Called Practical Inference". In: Practical Reason: Philosophical Papers of Georg Henrik von Wright, Volume I. Oxford: Basil Blackwell, 1983, 18-34.

Wittgenstein, L. (c. 1937-1938). “Appendix III”. In: Remarks on the Foundations of Mathematics (rev. ed.). Cambridge, Mass.; London, England: MIT Press, 1978, 116-117.

- (1963). Tractatus Logico-Philosophicus (2nd ed) (D. F. Pears and B. F. McGuinness, trans.). London, England: Routledge \& Kegan Paul Ltd.

- (1961). Notebooks 1914-1916. von Wright, Georg Henrik and Anscombe, G. E. M. (eds.) (G. E. M. Anscombe, trans.). Oxford: Basil Blackwell.

- (2009). Philosophical Investigations (rev. 4th ed.). Hacker, P. M. S. and Joachim Schulte, Joachim (eds.) (G. E. M. Anscombe, P. M. S. Hacker and Joachim Schulte, trans.). Oxford: Blackwell Publishing Ltd. 
Noam Melamed is a graduate student at the School of Philosophy, Linguistics and Science Studies at Tel Aviv University. His research focuses on intention, the concept of moral relations and the constitution of moral rationality.

Noam Melamed s'ha graduat i estudia a l'Escola de Filosofia, Lingüística i Ciències de la Universitat de Tel Aviv. La seva recerca se centra en la intenció, el concepte de relacions morals i la constitució de la racionalitat moral. 